\title{
Ethanol extracts of chickpeas alter the total lipid content and expression levels of genes related to fatty acid metabolism in mouse 3T3-L1 adipocytes
}

\author{
SHIGEO SHINOHARA ${ }^{1,2}$, YUANJUN GU $^{3}$, YING YANG ${ }^{4}$, YASUO FURUTA ${ }^{2}$, MASAHIKO TANAKA $^{2}$, \\ XIAOHUA YUE ${ }^{3}$, WEIQING WANG ${ }^{4}$, MASARU KITANO ${ }^{5}$ and HIROSHI KIMURA ${ }^{1}$ \\ ${ }^{1}$ Molecular Genetics in Medicine, Shiga University of Medical Science, Otsu, Shiga 520-2192; \\ ${ }^{2}$ Otsu Skin Care Research Institute, Nutraceuticals Division, Otsuka Pharmaceutical Co., Ltd., Otsu, Shiga 520-0002, Japan; \\ ${ }^{3}$ Jumpsun Bio-medicine (Shanghai) Co., Ltd., Shanghai 201101; ${ }^{4}$ Shanghai Clinical Center for Endocrine and \\ Metabolic Diseases, Ruijin Hospital, School of Medicine, Shanghai Jiaotong University, Shanghai 200025, P.R. China; \\ ${ }^{5}$ School of Communication and Design, College of Humanities, Shukutoku University, Saitama 354-8510, Japan
}

Received November 10, 2015; Accepted May 18, 2016

DOI: $10.3892 /$ ijmm.2016.2654

\begin{abstract}
Desi-type chickpeas, which have long been used as a natural treatment for diabetes, have been reported to lower visceral adiposity, dyslipidemia and insulin resistance induced by a chronic high-fat diet in rats. In this study, in order to examine the effects of chickpeas of this type in an in vitro system, we used the 3T3-L1 mouse cell line, a subclone of Swiss 3T3 cells, which can differentiate into cells with an adipocyte-like phenotype, and we used ethanol extracts of chickpeas (ECP) instead of chickpeas. Treatment of the 3T3-L1 cells with ECP led to a decrease in the lipid content in the cells. The desaturation index, defined as monounsaturated fatty acids (MUFAs)/ saturated fatty acids (SFAs), was also decreased by ECP due to an increase in the cellular content of SFAs and a decrease in the content of MUFAs. The decrease in this index may reflect a decreased reaction from SFA to MUFA, which is essential for fat storage. To confirm this hypothesis, we conducted a western blot analysis, which revealed a reduction in the amount of stearoyl-CoA desaturase 1 (SCD1), a key enzyme catalyzing the reaction from SFA to MUFA. We observed simultaneous inactivations of enzymes participating in lipogenesis, i.e., liver kinase B1 (LKB1), acetyl-CoA carboxylase (ACC) and AMPK, by phosphorylation, which may lead to the suppression of reactions from acetyl-CoA to SFA via malonyl-CoA in lipogenesis. We also investigated whether lipolysis is affected by ECP. The amount of carnitine palmitoyltransferase 1 (CPT1), an enzyme important for the oxidation of fatty acids, was increased by
\end{abstract}

Correspondence to: Mr Shigeo Shinohara, Otsu Skin Care Research Institute, Nutraceuticals Division, Otsuka Pharmaceutical Co., Ltd., Otsu, Shiga 520-0002, Japan

E-mail: shinohara.shigeo@gmail.com

Key words: chickpea, stearoyl-CoA desaturase 1, lipogenesis, lipolysis, liver kinase B1, acetyl-CoA carboxylase, AMP kinase, carnitine palmitoyltransferase 1 , uncoupling protein 2
ECP treatment. ECP also led to an increase in uncoupling protein 2 (UCP2), reported as a key protein for the oxidation of fatty acids. All of these results obtained regarding lipogenesis and fatty acid metabolism in our in vitro system are consistent with the results previously shown in rats. We also examined the effects on SCD1 and lipid contents of ethanol extracts of Kabuli-type chickpeas, which are used worldwide. The effects were similar, but of much lesser magnitude compared to those of ECP described above. Thus, Desi-type chickpeas may prove to be effective for the treatment of diabetes, as they can alter the lipid content, thus reducing fat storage.

\section{Introduction}

The number of obese individuals has rapidly increased in several countries due to changes in lifestyle and/or food consumption. Obesity is a serious disease that can shorten the lifespan of an individual by inducing insulin resistance, type 2 diabetes, dyslipidemia and atherosclerosis (1-3). Obesity is often defined as the excessive accumulation of visceral adipose tissue. In general, in the human body, if the energy intake exceeds the energy consumption, most of this excess energy will be accumulated as visceral adipocytes (particularly in white adipose tissue) in the form of triglycerides (TG) and cholesterol (CE) (4).

It is well known that a number of factors are involved in obesity (1-3). In adipose, hepatic and muscle tissues, TG and $\mathrm{CE}$ accumulate in the form of lipid droplets. The shape and fatty acid composition of these lipid droplets has become a focus of research $(5,6)$. The droplets may be closely related to obesity or insulin resistance (7-10). Many lipid droplets that have grown large in size can be seen in the white adipocytes of both humans and animal models with obesity. These lipid droplets in adipocytes have a core that is composed of TG and CE esters and is coated by a phospholipid monolayer associated with lipid droplet proteins, such as perilipin (PLIN) (5). Earlier research revealed that these proteins and the composition of these lipid droplets, defined as the desaturation index, which is described by the ratio of monounsaturated fatty acids (MUFAs) 
to saturated fatty acids (SFAs), plays a role in obesity which is the result of a high-fat diet $(11,12)$.

The major MUFAs oleate (C18:1n-9) and palmitoleate $(\mathrm{C} 16: 1 \mathrm{n}-7)$ are the main unsaturated components of intracellular lipid droplets within tissues which are responsible for adipose, hepatic and muscle lipogenesis. These MUFAs are transformed from SFAs, i.e., stearate (C18) and palmitate (C16), by stearoyl-CoA desaturase (SCD). It has become clear that SCD is closely associated with obesity and insulin resistance through the regulation of lipogenesis and lipid oxidation $(10,13)$. There are also some enzymes that regulate lipogenesis. Phosphorylated (p-)AMP kinase (p-AMPK) inhibits the activity of fatty acid synthase (FAS) to reduce the synthesis of SFA from malonyl-CoA and acetyl-CoA (14-16). On the other hand, $\mathrm{p}-\mathrm{AMPK}$ accelerates the phosphorylation of acetyl-CoA carboxylase (ACC) to suppress the synthesis of malonyl-CoA from acetyl-CoA $(14,16,17)$.

Lipolysis is also affected by several factors (18). The activity of carnitine palmitoyltransferase 1 (CPT1), which plays a role in the transport of fatty acids into the mitochondria, a site where the oxidation of fatty acids occurs, is suppressed by malonyl-CoA (19). The expression of uncoupling protein (UCP) accelerates energy consumption through the uncoupling of oxidative phosphorylation on mitochondrial membranes (18). The inhibition of the expression of the PLIN gene promotes lipolysis, which is thought to be due to increased mitochondrial access to fatty acid substrates through an increase in the surface area of lipid droplets (5).

In an aim to counteract the negative effects of a high-fat diet, chickpeas (C. arietinum) have been investigated for their abitity to alter lipid metabolism. Currently, there are two types of chickpeas, the Kabuli type and the Desi type. The Desi type has a darker color and smaller seeds, and they have been cultivated in Xinjiang (China) for over 2,500 years; they have also been used since ancient times in traditional Uighur medicine as a natural treatment for type 2 diabetes, obesity and hepatic steatosis (21). Previously, using a mouse model, we reported that insulin resistance, type 2 diabetes, dyslipidemia and obesity-associated atherosclerosis caused by a high-fat diet can be attenuated improved by the consumption of chickpeas (20). In our previous study, we used the Desi type of chickpeas. In the present study, we prepared ethanol extracts of chickpeas (ECP) using the Desi-type chickpeas for in vitro experiments. We used the mouse 3T3-L1 cell line, which can differentiate into cells with an adipose-like phenotype, in order to determine the effects of the chickpeas on fatty acid metabolism and to elucidate the underlying mechanisms. For comparison, we also used extracts of Kabuli-type chickpeas for some of our experiments.

\section{Materials and methods}

Materials. Mouse 3T3-L1 pre-adipocytes were obtained from the Health Science Research Resources Bank (Osaka, Japan). Dulbecco's modified Eagle's medium (DMEM) with L-glutamine, sodium pyruvate and non-fat dry milk were obtained from Nacalai Tesque (Kyoto, Japan). Gentamicin reagent solution (gentamicin sulfate, $10 \mathrm{mg} / \mathrm{ml}$ ), trypsin-EDTA $(0.25 \%$ trypsin, $1 \mathrm{mM}$ EDTA $\bullet 4 \mathrm{Na}, \mathrm{X} 1)$, calf serum, the TRIzol plus RNA purification kit, the superscript VILO cDNA synthesis kit and Prolong Gold Antifade Reagent were purchased from
Invitrogen (Carlsbad, CA, USA). Primers and SYBR-Green for reverse transcription-quantitative PCR (RT-qPCR) and Tris-buffered saline with Tween-20 (TBS-T) tablets, $\mathrm{pH} 7.6$ (100 tablets) were purchased from Takara Bio Inc. (Shiga, Japan).

Both types of chickpeas were obtained from Jumpsun Bio-medicine (Shanghai, China). Phosphate-buffered saline (PBS), chloroform, methanol, 99.5\% ethanol, isopropanol, formaldehyde and undecanoic acid were purchased from Wako Pure Chemical Industries (Osaka, Japan). Oil Red O was purchased from Sigma-Aldrich (St. Louis, MO, USA). M-PER ${ }^{\circledR}$ Mammalian Protein Extraction Reagent and the protein assay kit (BCA method) were obtained from Pierce/Thermo Scientific (Rockford, IL, USA). AMPK $\alpha$ (23A3) rabbit monoclonal antibody (mAb; \#2603), p-AMPK $\alpha$ (Thr172; 40H9) rabbit mAb (\#2535), ACC antibody (\#3662), p-ACC (Ser79) antibody (\#3661), PLIN (D418) antibody (\#3470), SCD1 (C12H5) rabbit mAb (\#2794), GAPDH (14C10) rabbit mAb (\#2118), liver kinase B1 (LKB1; D60C5) rabbit mAb (\#3047),p-LKB1 (Ser428; C67A3) rabbit $\mathrm{mAb}$ (\#3482), fatty acid synthase (FAS) antibody (\#3189), horseradish peroxidase (HRP)-linked anti-rabbit IgG antibody (\#7074), and HRP-linked anti-mouse IgG antibody (\#7076) were obtained from Cell Signaling Technology (Beverly, MA, USA). Anti-RPS18 antibody (HPA050159) was purchased from Atlas Antibodies (Stockholm, Sweden). CPT1 (H-40) antibody (sc-98834) and UCP2 (G-6) antibody (sc-390189) were purchased from Santa Cruz Biotechnology, Inc. (Dallas, TX, USA). Anti-elongation of very long chain fatty acids family member 6 (ELOVL6) antibody (ab69857) was purchased from Abcam (Cambridge, MA, USA).

Preparation of ECP. Desi-type chickpeas (50 g) cultivated in Xinjiang, China were crushed and extracted 3 times with $500 \mathrm{ml}$ of $99.5 \%$ ethanol for $3 \mathrm{~h}$ at $60^{\circ} \mathrm{C}$, and the filtrate was concentrated to $\leq 1 \%$ ethanol under reduced pressure at $60^{\circ} \mathrm{C}$. Following condensation, the moisture content was reduced to $<30 \%$ of the total weight. The solid content of the extracts was measured by the loss on a drying test in the Japanese Society of Pharmacopoeia (22), and adjusted to exactly $70 \%$ with water. These extracts were used as ECPs in the present study and diluted to $0.2-0.1 \%$ in culture medium before use. Kabuli-type chickpea extracts also prepared by the same method.

Cell culture and the differentiation of 3T3-L1 cells into adipocytes. The 3T3-L1 cells were grown in DMEM supplemented with $10 \%$ calf serum and $0.5 \mu \mathrm{g} / \mathrm{ml}$ gentamicin sulfate. For differentiation, 3T3-L1 confluent pre-adipocytes were treated for 2 days with DMEM supplemented with $10 \%$ fetal bovine serum (FBS) in the presence of adipogenic inducers $(0.5 \mathrm{mM}$ methylisobutylxanthine, $10 \mu \mathrm{M}$ dexamethasone and $5 \mu \mathrm{g} / \mathrm{ml}$ insulin), as previously described $(23,24)$. The cells were then maintained in DMEM supplemented with $10 \% \mathrm{FBS}, 0.5 \mu \mathrm{g} / \mathrm{ml}$ gentamicin sulfate and $5 \mu \mathrm{g} / \mathrm{ml}$ insulin for 6 days. The medium was changed every 2 days. The cells were grown at $37^{\circ} \mathrm{C}$ in $5 \% \mathrm{CO}_{2}$ with $100 \%$ humidity.

Oil Red $O$ staining and protein assay. The Oil Red O staining method was used to measure the cellular neutral lipid droplet accumulation. Following the culture of 3T3-L1 cells for 8 days for differentiation in the presence or absence of $0.02-0.1 \% \mathrm{ECP}$, the cells were washed twice with PBS on ice and fixed with 
$10 \%$ formaldehyde for $10 \mathrm{~min}$. The cells were then washed twice with PBS on ice and immersed in 60\% isopropanol for 1 min and stained with Oil Red O solution thereafter. The stock solution of the dye ( $3 \mathrm{mg} / \mathrm{ml}$ in isopropanol) was diluted to $60 \%$ with distilled water prior to use and allowed to stand for $20 \mathrm{~min}$ at room temperature.

After staining, the cells were washed with $60 \%$ isopropanol to remove unbound dye and rinsed twice with PBS on ice. Images were aquired under a 10x40 fluorescence microscope with bright-field illumination (All-in one fluorescence microscope BIOREVO BZ-9000; Keyence, Osaka, Japan). For the measurement of total dye incorporated into cellular lipid droplets, $2 \mathrm{ml}$ of isopropanol were added to each culture dish after the complete removal of PBS, and the culture dish was gyrated for $5 \mathrm{~min}$ at room temperature. Subsequently, $300 \mu \mathrm{l}$ of isopropanol were placed into each well of a 96-well plate, and the absorbance at $510 \mathrm{~nm}$ was measured with SpectraMax Paradigm ${ }^{\circledR}$ Multi-Mode Microplate Reader (Molecular Devices, Sunnyvale, CA, USA). The amounts of proteins were determined using BCA protein assay kits.

Gas chromatographic analysis of lipid extracts from cells. The sample preparation for the gas chromatography analysis was performed as previously described (25). Briefly, the cells were washed twice with PBS on ice, and total cellular lipids were extracted 3 times with chloroform:methanol $(2: 1, \mathrm{v} / \mathrm{v})$ containing n-undecanoic acid as an internal standard. The 3 lipid extracts were combined in a screw-capped glass tube and dried in a heating block under $\mathrm{N}_{2}$ gas flow at $40^{\circ} \mathrm{C}$. Fatty acid methyl esters were obtained by incubation with $3 \mathrm{M} \mathrm{HCl}$ in methanol and extracted with hexane. Fatty acid methyl esters were identified using a Hewlett-Packard 5890 gas chromatograph equipped with a 7673 auto injector and SP-2560 column, $75 \times 0.18 \mathrm{~mm}$ ID, $0.14 \mu \mathrm{m}$ (Sigma-Aldrich) connected to a flame ionization detector set at $220^{\circ} \mathrm{C}$. The column temperature was held at $180^{\circ} \mathrm{C}$ for $50 \mathrm{~min}$ after the injection. Under these conditions, the 16:0-, 16:1-, 18:0-, 18:1n-9- and 18:1n-7-methyl esters were eluted at 26.6, 29.3, 34.8, 38.4 and $39.0 \mathrm{~min}$, respectively.

Microarrays. A DNA microarray analysis was performed using Gene SQUARE, a multiple assay DNA microarray metabolic syndrome for mice (Kurabo Industries, Osaka, Japan) according to the manufacturer's instructions. Briefly, Alexa Fluor 555-labeled cDNA was prepared from $10 \mu \mathrm{g}$ of total RNA from each mouse tissue. Labeled cDNA was purified and then hybridized at $65^{\circ} \mathrm{C}$ for $14 \mathrm{~h}$. Following hybridization, the microarray slide was washed in several types of washing solution and dried by centrifugation at $450 \mathrm{x} \mathrm{g}$ and $20-25^{\circ} \mathrm{C}$ for $1 \mathrm{~min}$. The image of the microarray was acquired by a Genepix 4200A microarray scanner (Molecular Devices). The fluorescence intensities of the scanned images were quantified, corrected for background noise, and normalized by the intensity of Mus musculus ribosomal protein S18 (RPS18).

Western blot analysis. The cells grown in 100-mm dishes were washed twice with $10 \mathrm{ml}$ of PBS and lysed in $1 \mathrm{ml} \mathrm{M}$-PER. The resulting debris was removed by centrifugation at $15,000 \times \mathrm{g}$ for $10 \mathrm{~min}$ at $4^{\circ} \mathrm{C}$. Equal amounts of protein $(20 \mu \mathrm{g} / \mathrm{well})$ were applied to Any kD ${ }^{\mathrm{TM}}$ Mini-PROTEAN TGX Gels (Bio-Rad Laboratories, Hercules, CA, USA) and separated by poly- acrylamide gel electrophoresis (PAGE). Proteins on the gel were then transferred to PVDF membranes with an iBlot gel transfer system (Invitrogen) or a Trans-Blot Turbo Transfer system (Bio-Rad Laboratories).

After blocking with 5\% non-fat dry milk in TBS-T for $1 \mathrm{~h}$ at room temperature, the membranes were washed with TBS-T and incubated with the primary antibody against each protein listed above (see Materials section) and the secondary goat antibody against rabbit or mouse IgG conjugated to HRP. Visualization of the protein bands was performed by the reaction of HRP with SuperSignal West Dura Extended Duration Substrate (Thermo Fisher Scientific) and an LAS-3000 luminescent image analyzer (Fujifilm, Tokyo, Japan). A densitometric analysis of each band was performed with a Multi Gauge Version 2.1 (Fujifilm).

$R R-q P C R$. Total RNA was extracted from the 3T3-L1 cells using a TRIzol Plus RNA purification kit and then reverse transcribed into cDNA with the use of a SuperScript VILO cDNA synthesis kit. The abundance of transcripts was assessed by qPCR on a StepOne Plus (Applied Biosystems by Life Technologies, Foster City, CA, USA) with a SYBR-Green detection system. For each run, samples were analyzed in triplicate for both the gene of interest and the Mus musculus Rps18 gene as an internal control. The expression data for Scdl and Rps18 were normalized for the efficiency of amplification, as determined by a standard curve included on each run and analyzed using the $\Delta \Delta \mathrm{CT}$ method (31). The forward and reverse primers used were as follows: $S c d 1$, TCTTGT CCCTATAGCCCAATCCAG (forward) and AGCTCAGAGC GCGTGTTCAA (reverse); and Rps18, TTCTGGCCAACGGT CTAGACAAC (forward) and CCAGTGGTCTTGGTGTG CTGA (reverse).

Statistical analysis. The data were subjected to statistical analyses using SAS Release 9.1 (SAS Institute, Cary, NC, USA). The results from 3 experiments are presented as the means \pm standard deviation (SD). The statistical analyses were performed using the unpaired Student's t-test, One-Way ANOVA (Tukey) and the Jonckheere-Terpstra test. Values of $\mathrm{p}<0.05$ were considered to indicate statistically significant differences.

\section{Results}

Effects of ECP on the growth of the lipid droplets, and the lipid and PLIN contents. The 3T3-L1 cells cultured with or without ECP at $0.1 \%$ for 8 days were stained with Oil Red O (Fig. 1A). Large lipid droplets developed on day 8 when differentiation was completed without ECP. By contrast, only small droplets were observed in the presence of ECP at $0.1 \%$. The amount of dye incorporated into the cellular droplets was then measured as the absorbance at $510 \mathrm{~nm} / \mathrm{mg}$ protein (Fig. 1B). In the presence of ECP at $0.02-0.1 \%$, the lipid content per $\mathrm{mg}$ protein was reduced by $63-76 \%$. The amount of PLIN was reduced by $63-76 \%$ in the presence of ECP at $0.1 \%$ (Fig. 1C).

Effects of ECP on the fatty acid contents and desaturation index of the lipid droplets. A gas chromatography analysis was performed for cellular lipid droplets. The contents of each fatty acid and the sum total of each fatty acid are shown in Fig. 2. 

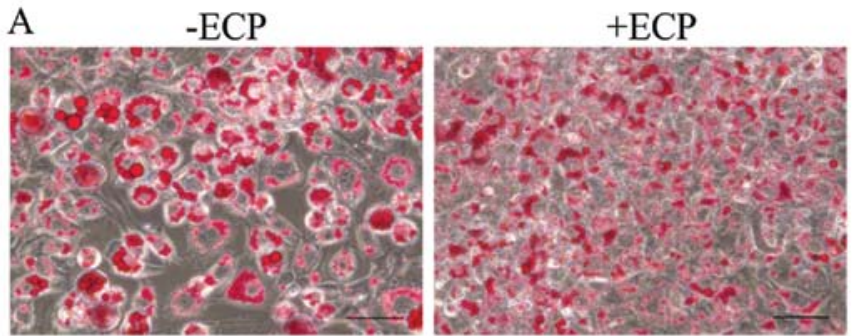

B

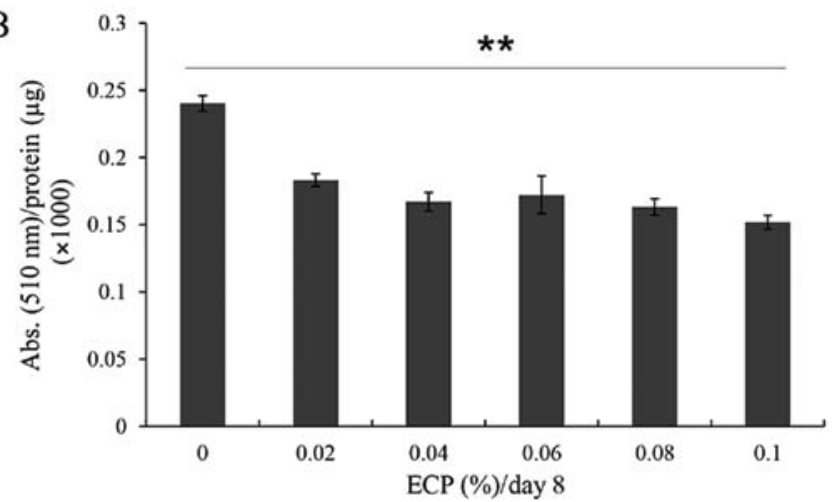

C

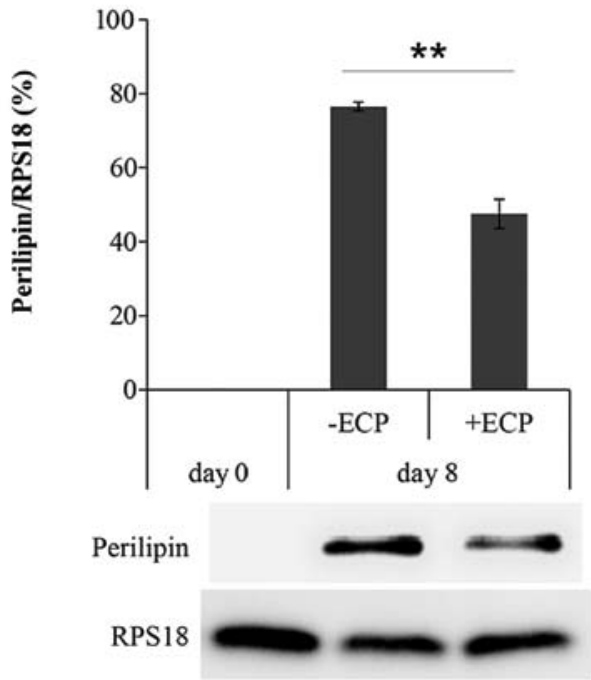

Figure 1. Effect of extracts of chickpeas (ECP) on lipid droplet formation and lipid contents. (A) Large droplets were observed after an 8-day culture for differentiation in the absence of ECP, whereas only small droplets were observed in the presence of ECP at $0.1 \%$ (scale bar, $20 \mu \mathrm{m}$ ). (B) After staining with Oil Red O, the absorbance of the dye at $510 \mathrm{~nm}$ was then measured and the absorbance $/ \mu \mathrm{g}$ protein was calculated $\left({ }^{* *} \mathrm{p}<0.0001\right.$; Jonckheere-Terpstra test). (C) The protein expression of perilipin was inhibited in the presence of ECP at $0.1 \%$ (** $\mathrm{p}=0.0002$-ECP vs. + ECP; unpaired Student's t-test, values are the means $\pm \mathrm{SD}$ of triplicate experiments).

The reduction by ECP at $0.02-0.1 \%$ of the sum total $(70-81 \%$ of sum total without ECP) was similar to that of the lipid contents measured by the OilRedO staining method(Fig. 1A). The contents of palmitate (C16:0), stearate (C18:0) and oleate (C18:1n-9) were slightly reduced by ECP at $0.02-0.1 \%$, whereas the contents of palmitoleate (C16:1) and vaccinate (C18:1n-7) were significantly reduced by the same ECP content.

The desaturation index values (the MUFA/SFA ratio for palmitoleate/palmitate, oleate/stearate and vaccenate/stearate) are shown in Table I. The ratio of palmitoleate/palmitate was markedly suppressed by the presence of ECP in a dose-
Table I. The desaturation index values: the MUFA/SFA ratio for palmitoleate/palmitate, oleate/stearate and vaccinate/stearate.

\begin{tabular}{lccc}
\hline ECP $(\%)$ & $\begin{array}{c}\text { Palmitoleate/ } \\
\text { palmitate } \\
\text { C16:1/C16:0 }\end{array}$ & $\begin{array}{c}\text { Oleate/ } \\
\text { stearate } \\
\text { C18:1n-9/C18:0 }\end{array}$ & $\begin{array}{c}\text { Vaccinate/ } \\
\text { stearate } \\
\text { C18:1n-7/C18:0 }\end{array}$ \\
\hline 0 & $1.19 \pm 0.08$ & $0.79 \pm 0.07$ & $0.16 \pm 0.04$ \\
0.02 & $1.03 \pm 0.05$ & $0.87 \pm 0.09$ & $0.13 \pm 0.01$ \\
0.04 & $0.85 \pm 0.03$ & $0.74 \pm 0.04$ & $0.14 \pm 0.01$ \\
0.06 & $0.77 \pm 0.08$ & $0.73 \pm 0.07$ & $0.14 \pm 0.02$ \\
0.08 & $0.64 \pm 0.05$ & $0.78 \pm 0.15$ & $0.22 \pm 0.11$ \\
0.10 & $0.56 \pm 0.06$ & $0.70 \pm 0.09$ & $0.19 \pm 0.02$ \\
\hline
\end{tabular}

The desaturation index (MUFAs/SFAs) was calculated for C16:1/C16:0 and $\mathrm{C} 18: 1 \mathrm{n}-9 / \mathrm{C} 18: 0$ from the results shown in Fig. 3. Values are the mean $\pm \mathrm{SD}$ of triplicate experiments $(\mathrm{C} 16: 1 / \mathrm{C} 16: 0, \mathrm{p}<0.0001$; $\mathrm{C} 18: 1 \mathrm{n}-9 / \mathrm{C} 18: 0, \mathrm{p}=0.0124$; $\mathrm{C} 18: 1 \mathrm{n}-7 / \mathrm{C} 18: 0, \mathrm{p}=0.0008$, JonckheereTerpstra test). MUFAs, monounsaturated fatty acids; SFA, saturated fatty acid; ECP, extracts of chickpeas.

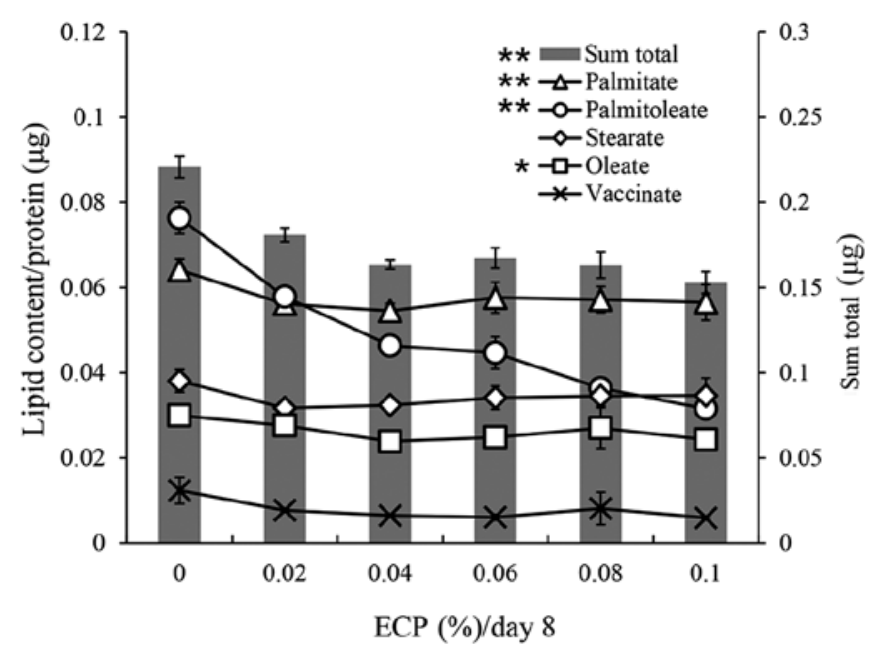

Figure 2. Changes in lipid composition by extracts of chickpeas (ECP) and the sum total of fatty acids. Total cellular lipids were extracted from cells cultured with or without ECP for 8 days, hydrolyzed to fatty acid, and then esterified to methyl ester form. The composition of the fatty acid methyl ester was analyzed by gas chromatography. Lipid contents for palmitate (C16:0), palmitoleate (C16:1), stearate (C18:0), oleate (C18:1n-9) and vaccinate (C18:1n-7) and the sum total are shown. (Values are the means \pm SD of triplicate experiments. ${ }^{* *} \mathrm{p}<0.01$ for $\mathrm{C} 16: 1$ and $\mathrm{C} 18: 1 \mathrm{n}-7$ and sum total. ${ }^{*} \mathrm{p}<0.05$ for $\mathrm{C} 18: 1 \mathrm{n}-9$. No significant difference for C16:0 or C18:0. All p-values were obtained by the Jonckheere-Terpstra test).

dependent manner, which reflects the significant reduction in palmitoleate by ECP, as shown in Fig. 2. The ratio of oleate/stearate was only slightly reduced by treatment with ECP.

Effects of ECP on the differentiation of 3T3-L1 cells. As the development of lipid droplets is associated with adipocyte differentiation (26), we examined the effects of $0.1 \%$ ECP on the expression of differentiation marker genes in 3T3-L1 cells in order to determine whether ECP affects differentiation itself. We used the Kurabo Gene SQUARE multiple-assay DNA microarray and focused on the expression levels of the 
Table II. The effects of ECP on the expression of differentiation marker genes.

\begin{tabular}{|c|c|c|c|c|c|c|c|c|c|c|c|c|}
\hline \multirow[b]{2}{*}{ Differentiation marker } & \multirow[b]{2}{*}{ Gene symbol } & \multicolumn{6}{|c|}{$-\mathrm{CP}$} & \multicolumn{5}{|c|}{$+\mathrm{CP}$} \\
\hline & & Day 0 & Day 1 & Day 2 & Day 4 & Day 6 & Day 8 & Day 1 & Day 2 & Day 4 & Day 6 & Day 8 \\
\hline \multirow[t]{2}{*}{ Early phase } & $\operatorname{Cebp} \beta$ & 1.0 & 2.2 & 2.8 & 2.5 & 3.1 & 3.3 & 3.1 & 3.8 & 2.9 & 3.1 & 3.8 \\
\hline & Cebpd & 1.0 & 1.0 & 1.0 & 1.2 & 2.6 & 1.0 & 0.9 & 0.9 & 1.4 & 1.9 & 1.1 \\
\hline \multirow[t]{2}{*}{ Late phase } & Cebpa & 1.0 & 1.3 & 3.0 & 4.2 & 8.7 & 5.9 & 1.3 & 3.2 & 4.9 & 6.5 & 8.8 \\
\hline & Ppar $\gamma$ & 1.0 & 1.0 & 2.1 & 12.0 & 11.2 & 9.9 & 1.0 & 4.5 & 9.7 & 10.8 & 13.2 \\
\hline
\end{tabular}

The expressions of $\operatorname{Cebp} \beta$ and $\operatorname{Cebp} \delta$ as early-differentiation markers and those of Cebp $\alpha$ and PPAR $\gamma$ as late-differentiation markers were determined by the microarray method. Each value is normalized to the value at day 0. ECP, extracts of chickpeas; Cebp $\beta$, CCAAT-enhancer-binding proteins $\beta$; Ppar $\gamma$, peroxisome proliferator-activated receptor $\gamma$.

A

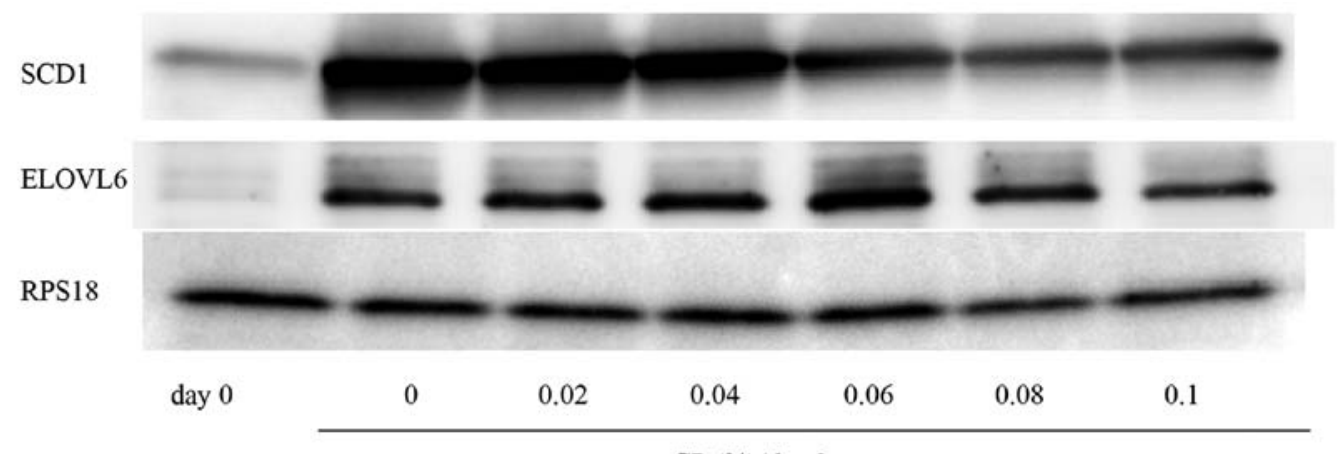

$\mathrm{CP}(\%) /$ day 8

B

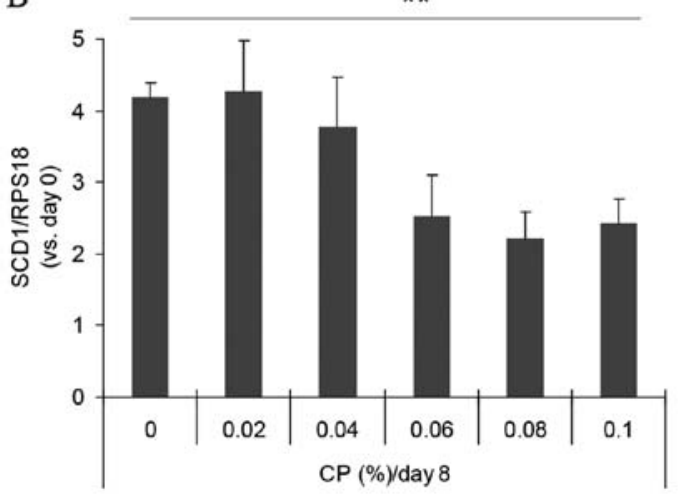

$\mathrm{C}$

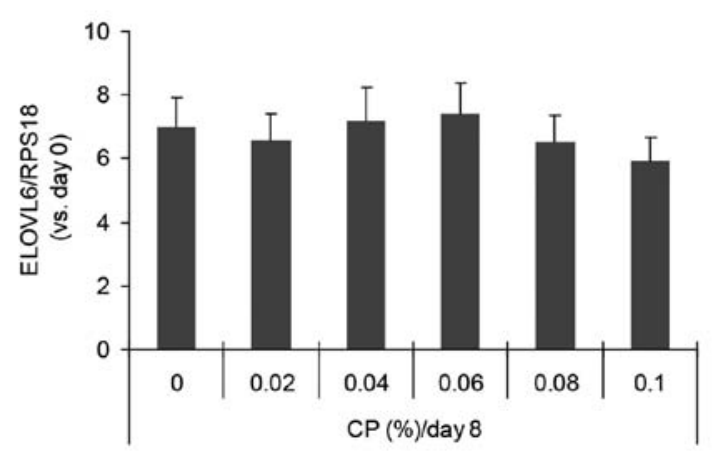

Figure 3. Effects of extracts of chickpeas (ECP, shown as CP) on stearoyl-CoA desaturase 1 (SCD1) and elongation of very long chain fatty acids family member 6 (ELOVL6).(A) Western blot analysis was performed for SCD1 and ELOVL6. (B and C) Densitometric analysis was performed by reading individual protein bands thereafter. Each value was corrected with an internal standard (RPS18), and the value relative to day 0 was then calculated [means \pm SD of triplicate experiments; (B) SCD1, ${ }^{* *} \mathrm{p}=0.0002$; (C) ELOVL6, $\mathrm{p}=0.1333$; Jonckheere-Terpstra test].

early differentiation marker genes, CCAAT-enhancer-binding protein (Cebp) $\beta$ and $C e b p \delta$, and the expression levels of the late differentiation marker genes, Cebp $\alpha$ and peroxisome proliferator-activated receptor $\gamma(P P A R \gamma)$. We compared the expression levels of each gene in the presence of ECP at $0.1 \%$ with those in the absence of ECP. For this purpose, we calculated the ratios of the gene expression levels with or without ECP on days $1-8 /$ those on day 0 . The ratios are shown in Table II. The expression level of each gene slightly or markedly increased during the 8-day culture for differentiation in the absence of ECP. The presence of ECP caused only slight differences in the ratio (Table II).
Effects of ECP on SCD1 and ELOVL6 and on the expression of the Scdl gene. Since SCD catalyzes the conversion from saturated fatty acids to unsaturated acids as a key enzyme of lipogenesis, this enzyme has been suggested to be involved in alterations of the desaturation index $(27,28)$. We therefore examined the amount of SCD1 protein by western blot analysis (Fig. 3A). The amount was increased by approximatelt 4-fold during culture for differentiation for 8 days, and this increase was suppressed in the presence of ECP at $0.06-0.1 \%$ (Fig. 3B). In all western blot analyses, we used RPS18 as the internal standard and observed no substantial alterations in the amount of this protein during differentiation. 
A

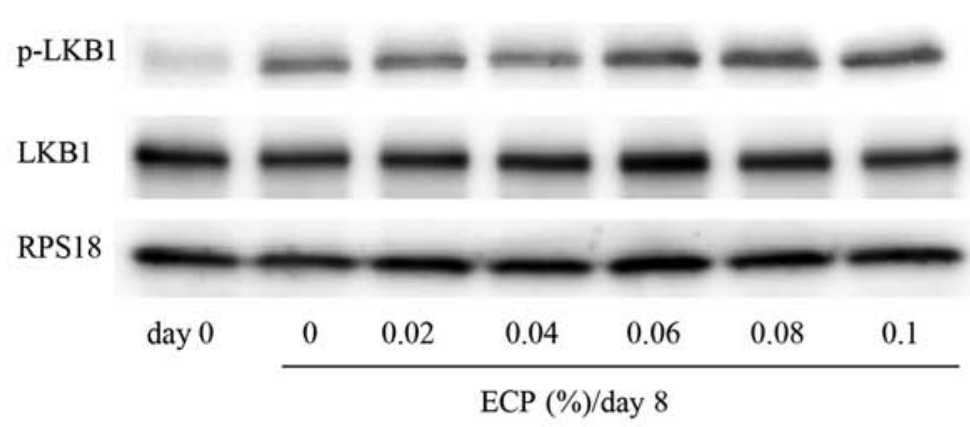

C

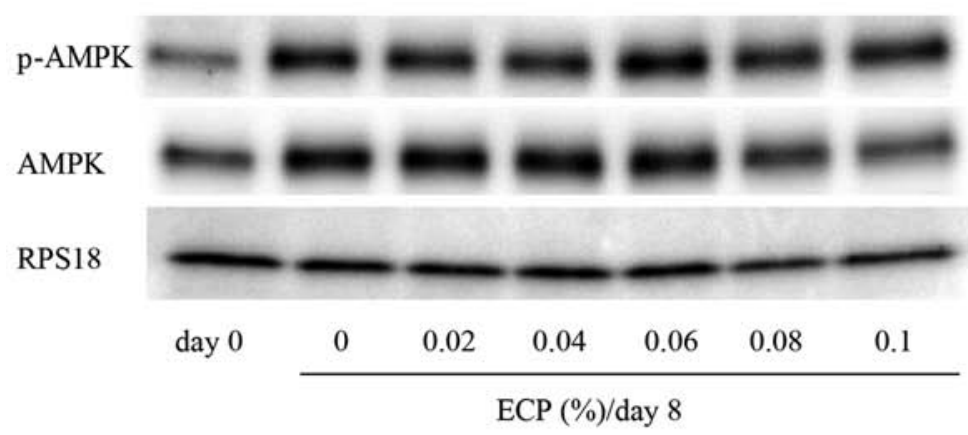

B

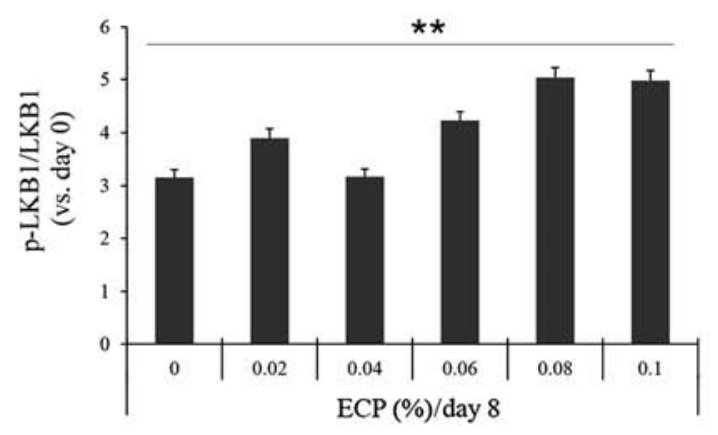

D

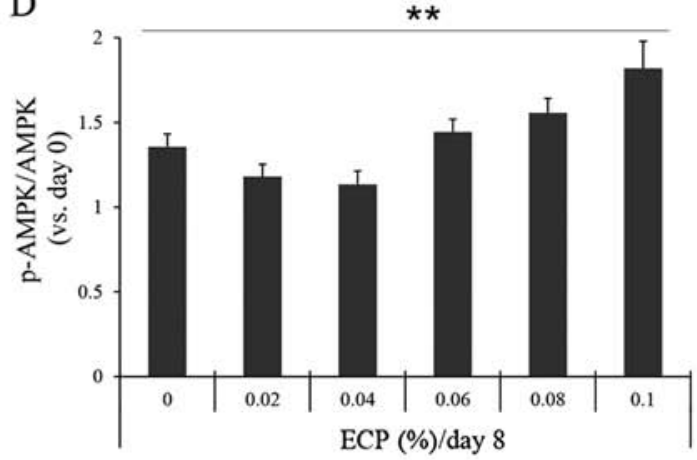

Figure 4. Effects of extracts of chickpeas (ECP) on the phosphorylation of liver kinase B1 (LKB1) and AMPK. Western blot analysis was performed for (A) LKB1 and (C) AMPK. (B and C) Densitometric analysis was performed by reading individual protein bands thereafter. Densitometric readings were performed on the bands of (B) LKB1 and p-LKB1 and those of (D) AMPK and p-AMPK. Each value was corrected with the internal standard RPS18, and each ratio (p-LKB1/LKB1 or p-AMPK/AMPK) was then calculated. Values are the means \pm SD of triplicate experiments (Jonckheere-Terpstra test: p-LKB1/ $\left.\mathrm{LKB} 1,{ }^{* *} \mathrm{p}=0.0002 ; \mathrm{p}-\mathrm{AMPK} / \mathrm{AMPK},{ }^{* *} \mathrm{p}=0.0011\right)$.

By contrast, the amounts of GAPDH and $\beta$-actin usually used as internal standards were altered during the differentiation of 3T3-L1 cells (data not shown). The effects of ECP on the expression of the $S c d l$ gene were also examined by RT-qPCR. The expression was suppressed to $89,75,64,73$ and $61 \%$ by ECP at $0.02,0.04,0.06,0.08$ and $0.1 \%$, respectively (data not shown). The amount of ELOVL6, a fatty acid elongase that uses malonyl-CoA as a two-carbon donor in the step of fatty acid elongation, was not altered by the presence of 0.02 $0.1 \%$ ECP (Fig. 3A and C).

Effects of ECP on other enzymes participating in lipogenesis. As the suppression of $S c d l$ gene expression often causes an increase in the phosphorylation of AMPK (p-AMPK) and ACC (p-ACC) $(19,29)$, and as the phosphorylated form of LKB1, the upstream kinase in the AMPK cascade, promotes the phosphorylation of AMPK (30), we examined the phosphorylation levels of these enzymes by western blot analysis (Figs. 4 and 5). The phosphorylation levels of LKB1, AMPK and ACC were significantly increased by the presence of $0.06-0.1 \%$ ECP (Figs. 4 and $5 \mathrm{~A}$ and B). The phosphorylation levels of LKB1 and AMPK were not significantly altered by ECP at 0.02 or $0.04 \%$ (Fig. 4). As it has been reported that the expression of FAS is suppressed by the phosphorylated form (31) and that FAS promotes a reaction, producing SFA from malonyl-CoA, we also examined the effects of ECP on the level of FAS. The amount of FAS was reduced by the presence of 0.02-0.1\% ECP (Fig. 5A and C).
Effects of ECP on enzymes participating in lipolysis. CPT1 is an enzyme that is important for lipid metabolism. It promotes the transport of long-chain fatty acids into the mitochondria (32). We thus examined the changes in the amount of CPT1 in the 3T3-L1 cells. On day 0, the 3T3-L1 cells had only a small amount of CPT1, but on day 8 when differentiation was complete, the cells exhibited an increased amount of CPT1 (Fig. 6A and B). The presence of $0.08-0.1 \%$ ECP caused a significant increase in the amount of CPT1 (Fig. 6A and B), although ECP at 0.02-0.06\% almost had no effect on the levels of CPT1. Mitochondrial UCP2, located mainly in brown fat cells, uncouples oxidative phosphorylation and is responsible for thermogenesis without the production of ATP. This enzyme has been suggested to promote the oxidation of fatty acids (33). Hence the effects of ECP on UCP2 were examined in this study. ECP at $0.02-0.1 \%$ increased the amount of UCP2 (Fig. 6C and D).

Effects of ethanol extracts of Kabuli-type chickpeas on SCD1 and lipid contents. We also prepared ethanol extracts of the Kabuli-type chickpeas using the same method as that used for the Desi-type chickpeas, as described in the Materials and methods, and we examined the effects of these extracts on CPT1 and lipid contents (Fig. 7). The results of western blot analysis revealed that the ethanol extracts of the Kabuli-type chicikpeas had less prominent effects on SCD1 expression, as compared to the Deci-type ECP (Fig. 7A and B). The lipid contents were reduced by the ethanol extracts of the 
A

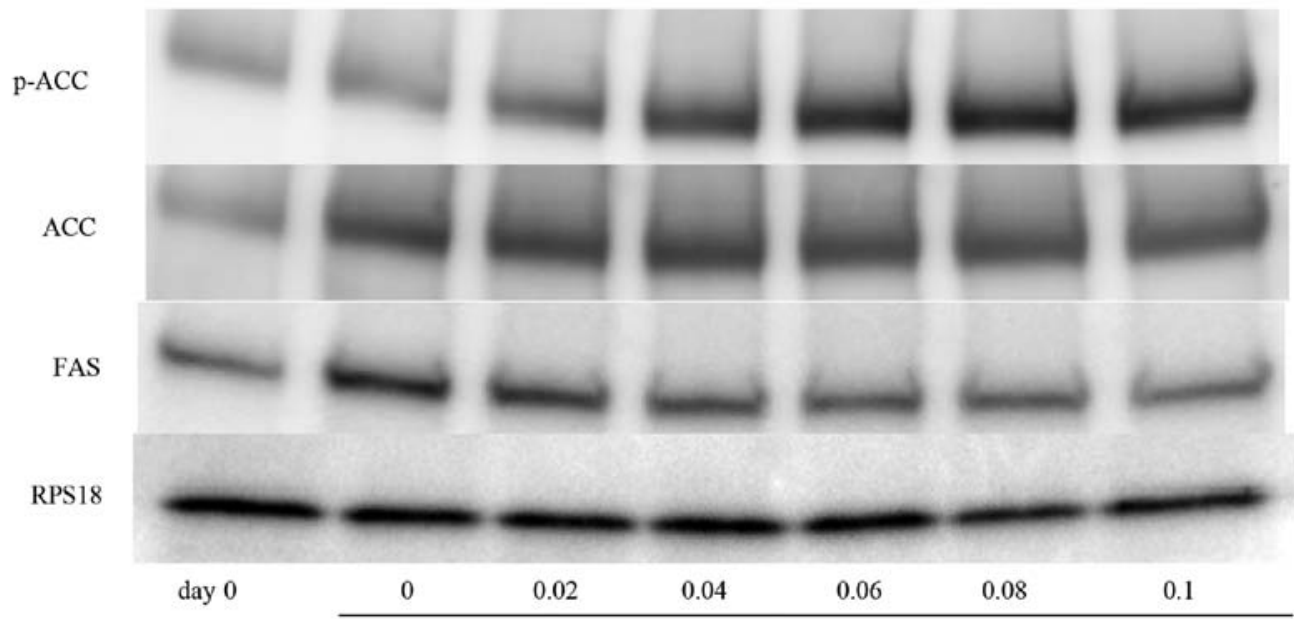

ECP (\%)/day 8
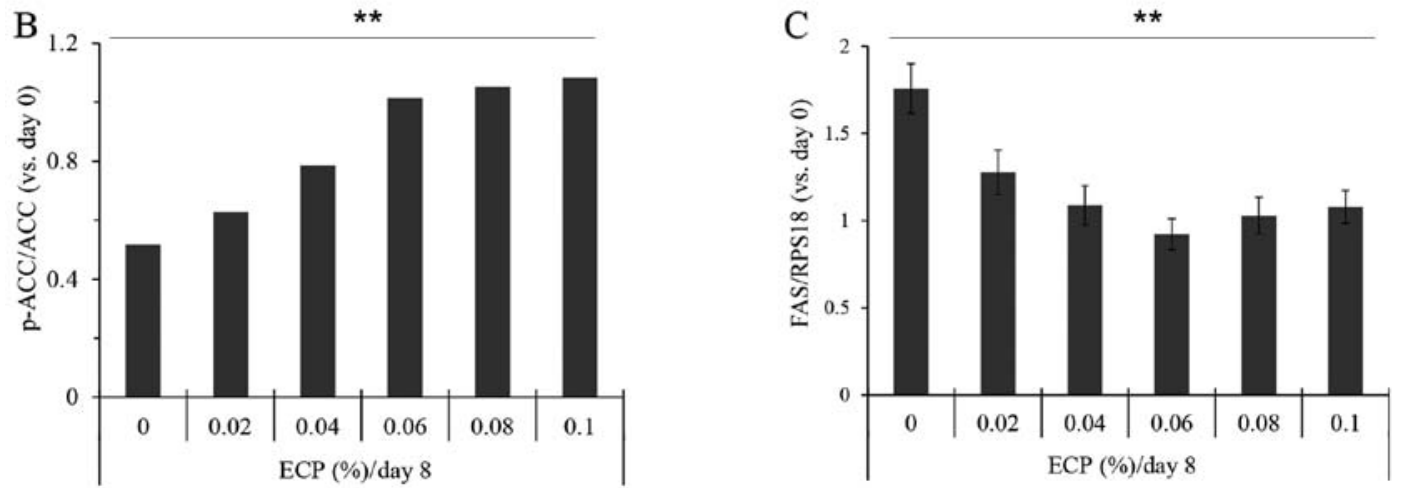

Figure 5. Effects of extracts of chickpeas (ECP) on the phosphorylation of acetyl-CoA carboxylase (ACC) and fatty acid synthase (FAS). (A) Western blot analysis was performed for ACC, p-ACC and FAS. (B and C) Densitometric analysis was performed by reading individual protein bands thereafter. Densitometric readings were performed on the bands of (B) ACC and p-ACC and those of (C) FAS. Each value was corrected with the internal standard RPS18, and the ratios (p-ACC/ACC) or values relative to day 0 (FAS) were then calculated. Values are the means \pm SD of triplicate experiments (Jonckheere-Terpstra test: p-ACC $/$ ACC, ${ }^{* *}$ p $<0.0001 ;$ FAS, ${ }^{* *} \mathrm{p}=0.005$ ).

A

CPTI

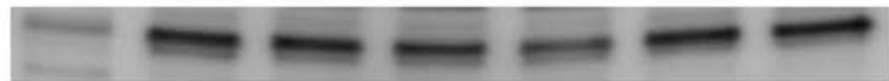

RPS18

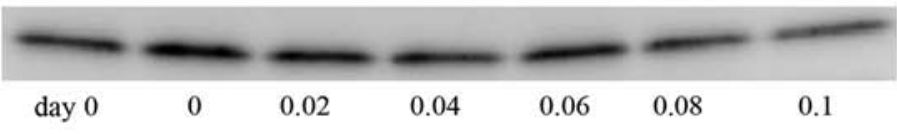

ECP (\%)/day 8

C

$\mathrm{UCP} 2$
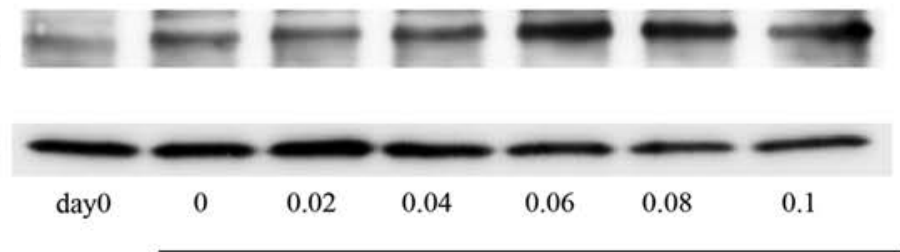

ECP $(\%) /$ day 8
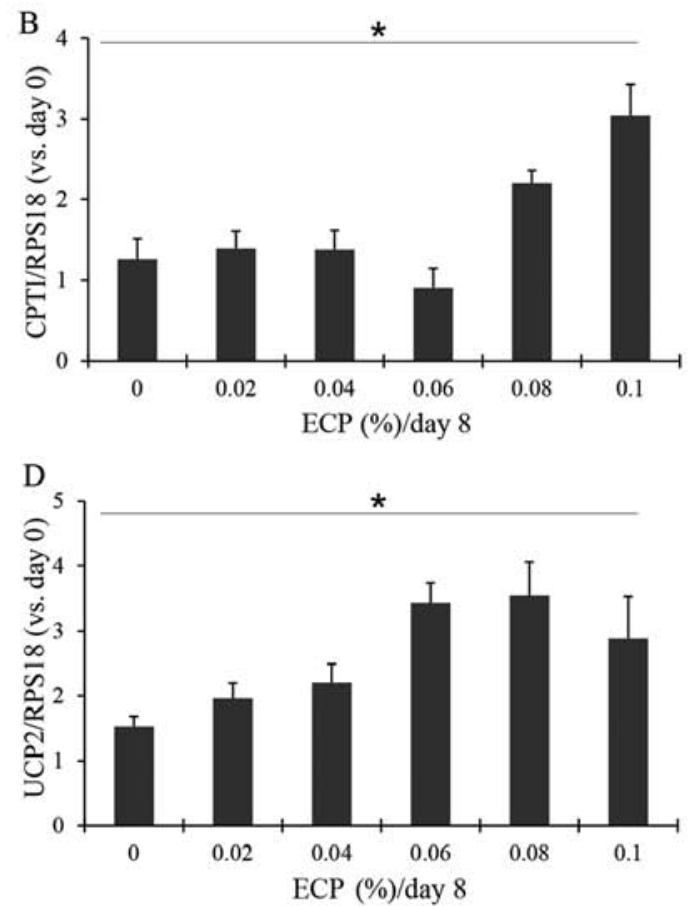

Figure 6. Effects of extracts of chickpeas (ECP) on carnitine palmitoyltransferase 1 (CPT1) and UCP2. Western blot analysis was performed for (A) CPT1 and (C) UCP2. (B and D) Densitometric analysis was performed by reading individual protein bands thereafter. Each value was corrected with the internal standard RPS18, and the value relative to day 0 was then calculated (means \pm SD of triplicate experiments; Jonckheere-Terpstra test: CPT1, ${ }^{*} \mathrm{p}=0.0124 ; \mathrm{UCP} 2,{ }^{*} \mathrm{p}=0.0369$ ). 
A

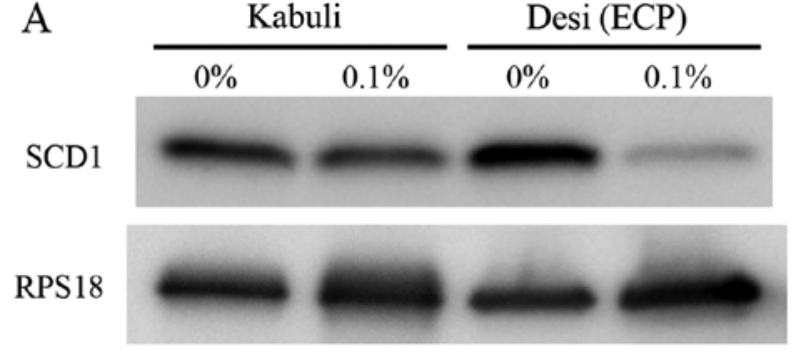

B

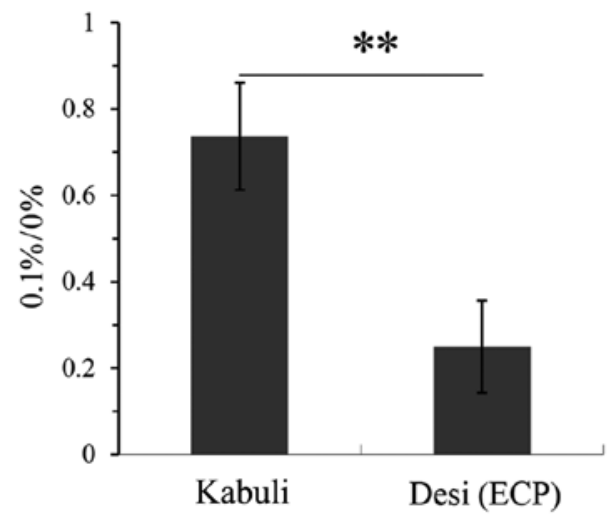

$\mathrm{C}$

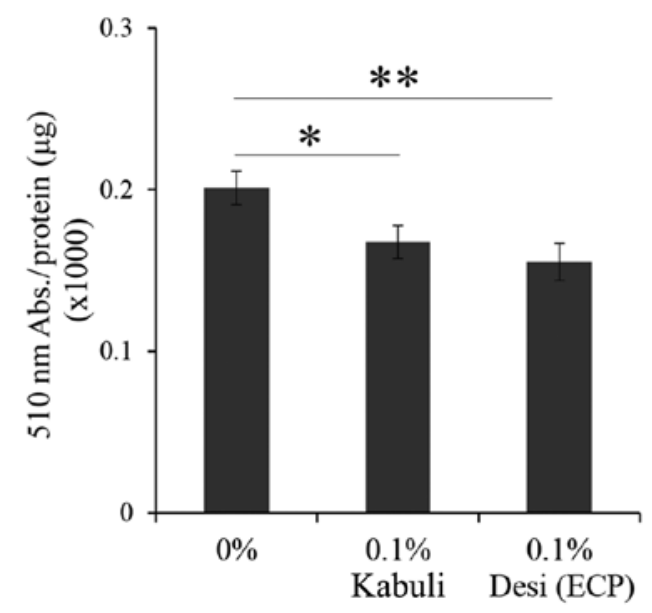

Figure 7. Effects of ethanol extracts of Kabuli-type chickpeas on stearoylCoA desaturase 1 (SCD1) and lipid contents. (A) After 8 days of culture with and without ethanol extracts of the Kabuli type or Desi type, the amount of SCD1 was examined by a western blot analysis (means \pm SD of triplicate experiments; ${ }^{* *} \mathrm{p}<0.05$, unpaired Student's t-test). (B) Densitometric analysis was performed by reading individual protein bands thereafter. (C) The lipid contents contained in 3T3-L1 cells after 8 days of culture with or without ethanol extracts of the Kabuli or Desi type were detected by measuring the absorbance at $510 \mathrm{~nm}$ with a fluorometer [means $\pm \mathrm{SD}$ of triplicate experiments; one-way ANOVA (Tukey), 0 vs. $0.1 \%$ Desi type ${ }^{* *} \mathrm{p}=0.0037 ; 0$ vs. $0.1 \%$ Kabuli type * $\mathrm{p}=0.0429$ ].

Kabuli-type chickpeas at $0.1 \%$ (Fig. 7C). However, this reduction was less prominent than that induced by the Deci-type ECP (Fig. 7C).

\section{Discussion}

Kabuli-type chickpeas are presently grown in many temperatezone countries, and the smaller, darker Desi type is grown only in Xinjiang, China and a few areas in India, in the semi-arid tropics. In a previous study, we used the Desi-type chickpeas obtained from Xinjiang Uighur and also used a mouse model of diabetes, and our findings indicated that several dysfunctions associated with obesity were improved by the Desi-type chickpeas (20). The results of the present study demonstrated that ethanol extracts of Desi-type chickpeas affected fatty acid metabolism in 3T3-L1 cells, indicating that the effects of Desitype chickpeas observed in our previous mouse model may be attributed at least in part to fatty acid metabolism at the cellular level.

We also used the Kabuli type, which had significant, but yet limited effects on cellular lipid contents and the amount of SCD1 (Fig. 7). It is thus possible that a long period of geographic isolation may have caused differences in the quantity and/or quality of the effects of the two types of chickpeas on obesity and fatty acid metabolism. The differences in the effects of the two types of chickpeas could also explain the reason why Desi-type chickpeas have been used as traditional Uighur medicine for patients with type 2 diabetes, obesity and hepatic steatosis (21). There are studies demonstrating that a diet containing chickpeas leads to small improvements in glucose tolerance, the serum lipids profile and/or hypercholesterolemia, although the studies do not describe the type of chickpeas used (32-36).

In the present study, in the presence of adipogenic inducers for 8 days, the 3T3-L1 cells differentiated into adipocytes. During this period, it was established that there is an induction of the expression of differentiation marker genes (37-39). As shown in Table II, the expression levels of early differentiation marker genes $(C e b p \beta$ and $C e b p \delta)$ and late differentiation marker genes $(C e b p \alpha$ and $P P A R \gamma)$ were increased during culture. ECP did not significantly alter the expression levels of these genes (Table II), indicating that ECP did not influence 3T3-L1 cell differentiation itself.

Our microscopic analysis revealed that there was a large number of ECP-treated cells with small-sized intracellular lipid droplets, whereas large lipid droplets were found inside normally differentiated adipocytes (Fig. 1A). As reported previously, small multilocular lipid droplets produced in the endoplasmic reticulum grow into unilocular lipid droplets in the cytoplasm by fusing $(8,9,40)$. During this enlargement process, it seems to be essential for lipid droplet coat proteins such as PLIN and FSP27 to coat the surface of the lipid droplets (9). In the present study, we observed that the amount of PLIN was significantly decreased by ECP (Fig. 1C and D). It is thus possible that a decrease in the amount of PLIN interferes with the growth of large unilocular droplets. Of note, smaller forms of droplets have been reported to allow for a larger total surface, which increases the mitochondrial access to fatty acid substrates, thereby promoting lipid oxidation (9). However, we have no data on lipid oxidation at present.

It is well known that there is a key enzyme that controls lipid metabolism (41). As illustrated in Fig. 8, SCD is an enzyme that converts SFAs, i.e., palmitic acid (C16:0) and stearic acid (C18:0), to produce MUFAs, i.e., palmitoleic acid (C16:1) and oleic acid (C18:1n-9), respectively. Under conditions in which the expression of $S c d l$ is suppressed, the desaturation index (MUFAs/FSA) is decreased (42). The genetic expression of SCD1, one of four isoforms of this enzyme, is regulated by insulin and leptin (43-45). An enhanced expression of SCD1 leads to the accumulation of fat in adipose, hepatic and muscle 


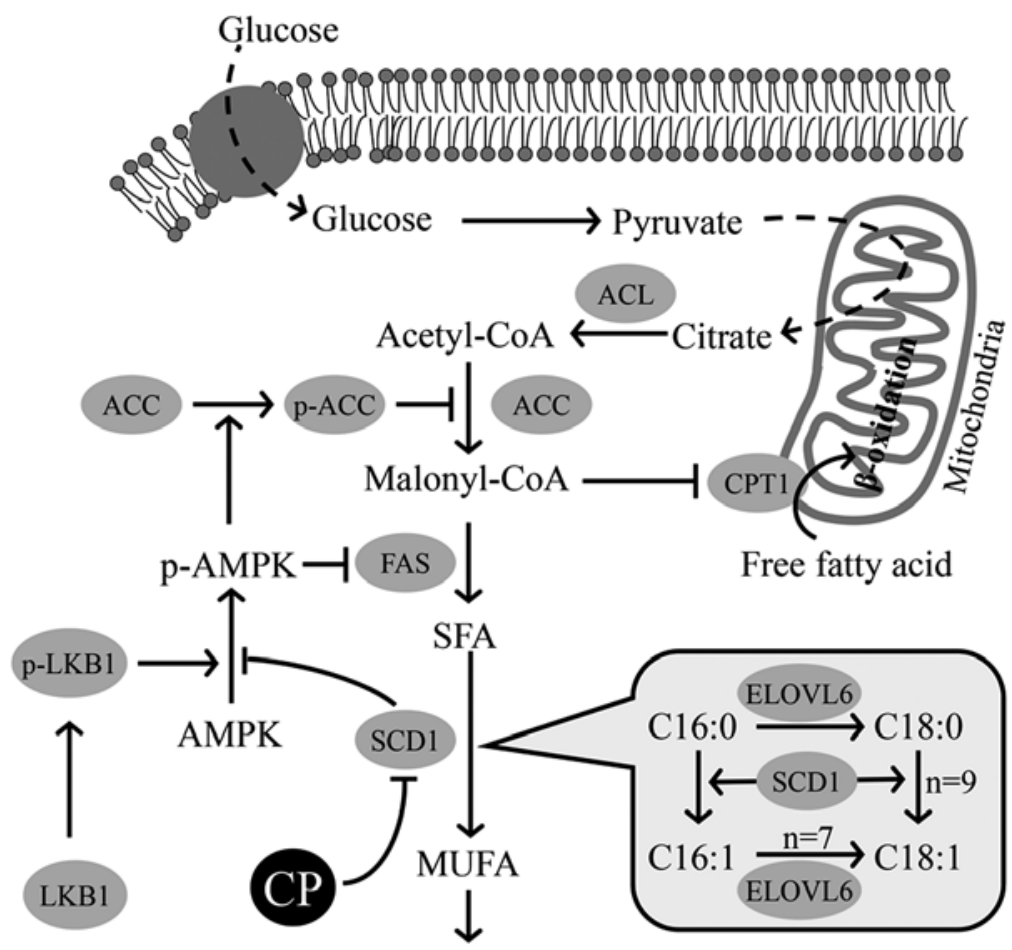

Fat storage

Figure 8. Hypothetical regulation of lipogenesis and lipolysis by stearoyl-CoA desaturase 1 (SCD1) and other enzymes. The hypothetical regulation of lipogenesis and lipolysis by extracts of chickpeas (ECP), based on our findings in this study. Three enzymes, acetyl-CoA carboxylase (ACC), fatty acid synthase (FAS) and SCD1, participating in lipogenesis in each step are described. SCD1 promotes the desaturation of saturated fatty acid (SFA) of liver kinase B1 (LKB1), causing an increase in the phosphorylation of AMP activated protein kinase (AMPK). The phosphorylated form of AMPK then promotes the phosphorylation of ACC to inactivate ACC, thereby suppressing the reaction from acetyl-CoA to malonyl-CoA. The depletion of malonyl-CoA simulates the transportation of fatty acids into the mitochondria by carnitine palmitoyltransferase 1 (CPT1). SCD1 itself catalyzes the reaction from SFA (16:0, 18:0) to MUFA (16:1, 18:1), as shown in the balloon. p-AMPK, phospho-AMPK; p-ACC, phospho-ACC; ACL, ATP citrate lyase; ELOVL6, elongation of very long chain fatty acids family member 6; MUFA, monounsaturated fatty acid.

tissue $(43,44,46)$. The deletion of $S c d 1$ in mice causes resistance to high-fat diet-induced obesity and glucose intolerance (42).

As shown in Fig. 2, the contents of SFAs (C16:0, C18:0) were not markedly affected by ECP, whereas those of MUFAs (C16:1, C18:1n-7, C18:1n-9) were decreased by ECP. These results are well reflected by the gradual decrease in the desaturation index with the increasing ECP concentration (Table I). Simultaneously, ECP suppressed the gene expression of $S c d 1$ and the amount of SCD1 (Fig. 3A and B), indicating that the suppression may lead to a decrease in the desaturation index. On the other hand, there no effect of ECP on ELOVL6 was observed, which catalyzes the conversion of $\mathrm{C} 16: 0$ or $\mathrm{C} 16: 1$ to C18:0 or C18:1 (Fig. 3A and C). These results may explain the decreases in the lipid contents and desaturation index in the ECP-treated cells. Of note, the desaturation index has been reported to have a proportional association with human plasma triglycerides (47) and Scdl mRNA (42).

As schematically depicted in Fig. 8, we suggest that the phosphorylation of AMPK is induced by a phosphorylated form of LKB1, which leads to the suppression in the production of SFA from malonyl-CoA by FAS and to the suppression of the production of malonyl-CoA from Acetyl-CoA by ACC $(19,29,41)$. ECP promoted the phosphorylation of LKB1, AMPK and ACC and reduced the amount of FAS (Figs. 4 and 5). The administration of ECP thus resulted in a series of these changes, as well as in decreased levels of SCD1 to reduce lipogenesis, although it is not yet clear whether each enzyme is directly or indirectly affected by ECP.

It has been reported that the expression of CPT1, an enzyme facilitating the transportation of fatty acids into the mitochondria, is regulated by the amount of malonyl-CoA and that the expression has a positive correlation with $\beta$-oxidation in the mitochondria $(48,49)$. As suggested above, malonyl-CoA can be depleted to a certain extent by the inhibitory effects of ECP on lipogenesis. It is therefore possible that the increased amount of CPT1 shown in Fig. 6A and B is due to decreased levels of malonyl-CoA and that $\beta$-oxidation is promoted. On the other hand, as UCP2 promotes the consumption of fatty acids without the formation of ATP $(50,51)$, an increase caused by ECP in the amount of UCP2 may result in the consumption. These two results suggest that lipolysis may be promoted by ECP.

In the present study, ethanol extracts of chickpeas, particularly those of the Desi type (which has been used as food for the control of obesity in a restricted region) were shown to have effects on several steps in lipid metabolism in an in vitro system. These effects were suppressive effects on the storage of fat. The suppression of each step in lipogenesis may result in a reduction in fat storage (29). The accumulation of droplets with small sizes and increased amounts of CPT1 and UCP2 may facilitate the consumption of fat. However, the mechanisms underlying these broad effects of ECP on lipid metabolism are not clear at present. 
As previously reported $(41,52)$, the regulation of SCD1 has become an interesting focus of attention as a potential treatment for the prevention of metabolic syndrome due to diet-induced obesity, hepatic steatosis and insulin resistance. SCD1 may be a key factor in lipid metabolism, and its reduction may result in the promoted phosphorylation of LKB1 (Fig. 4A and B). As previously reported (29), the phosphorylation of ACC may reduce the amount of malonyl-CoA and may lead to an increase in the amount of CPT1 (Fig. 5B). All of these findings suggest that at least a part of the effectiveness of ECP against visceral adiposity, dyslipidemia and insulin resistance that has been shown in mice (20) can be explained by the effects of ECP on lipid metabolism shown in the present experiments.

We have almost no information about the molecular basis of the effects of the ethanol extracts. However, we observed slight effects with the water soluble fraction and some effects with the chloroform soluble fraction (data not shown), after the ECP was shaken with chloroform. Several types of fatty acids and unsaturated fatty acids, including linoleic acid are found in the chloroform soluble fraction on a thin layer chromatograph. Of note, conjugated linoleic acid has been reported to have suppressive effects on SCD1 $(53,54)$. We have not performed an experiment to determine whether linoleic acid isolated from the ethanol extracts exerts effects on SCD1 levels. However, it is possible that unsaturated fatty acids such as linoleic acid participate in the effects of ECP.

Thus, it can be concluded that some contents of Desi-type of chickpeas may alter lipid metabolism, reducing the lipid content, and these chickpease may prove to be effective in the prevention of diabetes.

\section{Acknowledgements}

We would like to thank E. Ueno and J. Kako at Otsuka Pharmaceutical Co., Ltd. for providing advice and technical solutions for this study. We would also like to thank A. Shinohara and R. Moyer for their assistance with the translation of this study into English.

\section{References}

1. Flegal KM, Carroll MD, Ogden CL and Johnson CL: Prevalence and trends in obesity among US adults, 1999-2000. JAMA 288 : 1723-1727, 2002.

2. Kopelman PG: Obesity as a medical problem. Nature 404: 635-643, 2000

3. Kahn BB and Flier JS: Obesity and insulin resistance. J Clin Invest 106: 473-481, 2000.

4. Wajchenberg BL: Subcutaneous and visceral adipose tissue: their relation to the metabolic syndrome. Endocr Rev 21: 697-738, 2000

5. Brasaemle DL: Thematic review series: adipocyte biology. The perilipin family of structural lipid droplet proteins: stabilization of lipid droplets and control of lipolysis. J Lipid Res 48: 2547-2559, 2007.

6. Londos C, Brasaemle DL, Gruia-Gray J, Servetnick DA, Schultz CJ,Levin DM and Kimmel AR: Perilipin: Unique proteins associated with intracellular neutral lipid droplets in adipocytes and steroidogenic cells. Biochem Soc Trans 23: 611-615, 1995.

7. Ducharme NA and Bickel PE: Lipid droplets in lipogenesis and lipolysis. Endocrinology 149: 942-949, 2008.

8. Puri V and Czech MP: Lipid droplets: FSP27 knockout enhances their sizzle. J Clin Invest 118: 2693-2696, 2008.

9. Nishino N, Tamori Y, Tateya S, Kawaguchi T, Shibakusa T, Mizunoya W, Inoue K, Kitazawa R, Kitazawa S, Matsuki Y, et al: FSP27 contributes to efficient energy storage in murine white adipocytes by promoting the formation of unilocular lipid droplets. J Clin Invest 118: 2808-2821, 2008.
10. Flowers MT, Miyazaki M, Liu X and Ntambi JM: Probing the role of stearoyl-CoA desaturase-1 in hepatic insulin resistance. J Clin Invest 116: 1478-1481, 2006.

11. Flowers MT: The delta9 fatty acid desaturation index as a predictor of metabolic disease. Clin Chem 55: 2071-2073, 2009.

12. Jeyakumar SM, Lopamudra P, Padmini S, Balakrishna N, Giridharan NV and Vajreswari A: Fatty acid desaturation index correlates with body mass and adiposity indices of obesity in Wistar NIN obese mutant rat strains WNIN/Ob and WNIN/GR-Ob. Nutr Metab (Lond) 6: 27, 2009.

13. Dobrzyn A and Ntambi JM: Stearoyl-CoA desaturase as a new drug target for obesity treatment. Obes Rev 6: 169-174, 2005.

14. Motoshima H, Goldstein BJ, Igata M and Araki E: AMPK and cell proliferation - AMPK as a therapeutic target for atherosclerosis and cancer. J Physiol 574: 63-71, 2006.

15. Foretz M, Carling D, Guichard C, Ferré P and Foufelle F: AMP-activated protein kinase inhibits the glucose-activated expression of fatty acid synthase gene in rat hepatocytes. J Biol Chem 273: 14767-14771, 1998.

16. Woods A, Azzout-Marniche D,Foretz M,Stein SC,LemarchandP, Ferré P, Foufelle F and Carling D: Characterization of the role of AMP-activated protein kinase in the regulation of glucoseactivated gene expression using constitutively active and dominant negative forms of the kinase. Mol Cell Biol 20: 6704-6711, 2000.

17. Xiang X, Saha AK, Wen R, Ruderman NB and Luo Z: AMP-activated protein kinase activators can inhibit the growth of prostate cancer cells by multiple mechanisms. Biochem Biophys Res Commun 321: 161-167, 2004

18. Ahmadian M, Duncan RE and Sul HS: The skinny on fat: lipolysis and fatty acid utilization in adipocytes. Trends Endocrinol Metab 20: 424-428, 2009.

19. Dobrzyn P, Dobrzyn A, Miyazaki M, Cohen P, Asilmaz E, Hardie DG, Friedman JM and Ntambi JM: Stearoyl-CoA desaturase 1 deficiency increases fatty acid oxidation by activating AMP-activated protein kinase in liver. Proc Natl Acad Sci USA 101: 6409-6414, 2004.

20. Yang Y, Zhou L, Gu Y, Zhang Y, Tang J, Li F, Shang W, Jiang B, Yue $\mathrm{X}$ and Chen M: Dietary chickpeas reverse visceral adiposity, dyslipidaemia and insulin resistance in rats induced by a chronic high-fat diet. Br J Nutr 98: 720-726, 2007.

21. Committee of Chinese Pharmacopoeia: Chinese pharmacopoeia commission of sanitary ministry of People's Republic of China. Chinese Pharmacopoeia. In: Uigur Pharmacopoeia Fascicule. Xinjiang Science and Technology Sanitation Publisher, Xinjiang, p114, 1998.

22. The Society of Japanese Pharmacopoeia: The Japanese Pharmacopoeia. 15th edition. Yakuji Nippo, Tokyo, p44, 2006.

23. Hummasti S, Laffitte BA, Watson MA, Galardi C, Chao LC, Ramamurthy L, Moore JT and Tontonoz P: Liver X receptors are regulators of adipocyte gene expression but not differentiation: Identification of apoD as a direct target. J Lipid Res 45: 616-625, 2004.

24. Wang F and Tong Q: Transcription factor PU.1 is expressed in white adipose and inhibits adipocyte differentiation. Am J Physiol Cell Physiol 295: C213-C220, 2008.

25. Kim YC, Gomez FE, Fox BG and Ntambi JM: Differential regulation of the stearoyl-CoA desaturase genes by thiazolidinediones in 3T3-L1 adipocytes. J Lipid Res 41: 1310-1316, 2000.

26. Mackall JC, Student AK, Polakis SE and Lane MD: Induction of lipogenesis during differentiation in a 'preadipocyte' cell line. J Biol Chem 25: 6462-6464, 1976.

27. Enoch HG, Catalá A and Strittmatter P: Mechanism of rat liver microsomal stearyl-CoA desaturase. Studies of the substrate specificity, enzyme-substrate interactions, and the function of lipid. J Biol Chem 251: 5095-5103, 1976.

28. Miyazaki M, Bruggink SM and Ntambi JM: Identification of mouse palmitoyl-coenzyme A $\Delta 9$-desaturase. J Lipid Res 47 : 700-704, 2006.

29. Scaglia N, Chisholm JW and Igal RA: Inhibition of stearoylCoA desaturase-1 inactivates acetyl-CoA carboxylase and impairs proliferation in cancer cells: Role of AMPK. PLoS One 4: e6812, 2009.

30. Woods A, Johnstone SR, Dickerson K, Leiper FC, Fryer LG, Neumann D, Schlattner U, Wallimann T, Carlson M and Carling D: LKB1 is the upstream kinase in the AMP-activated protein kinase cascade. Curr Biol 13: 2004-2008, 2003.

31. Zhang BB, Zhou G and Li C: AMPK: An emerging drug target for diabetes and the metabolic syndrome. Cell Metab 9: 407-416, 2009. 
32. Lane MD1, Wolfgang M, Cha SH and Dai Y: Regulation of food intake and energy expenditure by hypothalamic malonyl-CoA. Int J Obes (Lond) 32 (Suppl 4): S49-S54, 2008.

33. Schrauwen P and Hesselink M: UCP2 and UCP3 in muscle controlling body metabolism. J Exp Biol 205: 2275-2285, 2002.

34. Pittaway JK, Ahuja KD, Robertson IK and Ball MJ: Effects of a controlled diet supplemented with chickpeas on serum lipids, glucose tolerance, satiety and bowel function. J Am Coll Nutr 26: 334-340, 2007.

35. Pittaway JK, Robertson IK and Ball MJ: Chickpeas may influence fatty acid and fiber intake in an ad libitum diet, leading to small improvements in serum lipid profile and glycemic control. J Am Diet Assoc 108: 1009-1013, 2008.

36. Zulet MA and Martinez JA: Corrective role of chickpea intake on a dietary-induced model of hypercholesterolemia. Plant Foods Hum Nutr 48: 269-277, 1995.

37. Tanaka T, Yoshida N, Kishimoto T and Akira S: Defective adipocyte differentiation in mice lacking the $\mathrm{C} / \mathrm{EBPbeta}$ and/or C/EBPdelta gene. EMBO J 16: 7432-7443, 1997.

38. Rosen ED, Sarraf P, Troy AE, Bradwin G, Moore K, Milstone DS Spiegelman BM and Mortensen RM: PPAR gamma is required for the differentiation of adipose tissue in vivo and in vitro. Mol Cell 4: 611-617, 1999.

39. Linhart HG, Ishimura-Oka K, DeMayo F, Kibe T, Repka D Poindexter B, Bick RJ and Darlington GJ: C/EBPalpha is required for differentiation of white, but not brown, adipose tissue. Proc Natl Acad Sci USA 98: 12532-12537, 2001.

40. Puri V, Konda S, Ranjit S, Aouadi M, Chawla A, Chouinard M, Chakladar A and Czech MP: Fat-specific protein 27, a novel lipid droplet protein that enhances triglyceride storage. J Biol Chem 282: 34213-34218, 2007.

41. Ntambi JM and Miyazaki M: Regulation of stearoyl-CoA desaturases and role in metabolism. Prog Lipid Res 43: 91-104, 2004.

42. Peter A, Cegan A, Wagner S, Lehmann R, Stefan N, Königsrainer A, Königsrainer I, Häring HU and Schleicher E: Hepatic lipid composition and stearoyl-coenzyme A desaturase $1 \mathrm{mRNA}$ expression can be estimated from plasma VLDL fatty acid ratios. Clin Chem 55: 2113-2120, 2009

43. Ntambi JM, Miyazaki M, Stoehr JP, Lan H, Kendziorski CM, Yandell BS, Song Y, Cohen P, Friedman JM and Attie AD: Loss of stearoyl-CoA desaturase-1 function protects mice against adiposity. Proc Natl Acad Sci USA 99: 11482-11486, 2002.
44. Cohen P, Miyazaki M, Socci ND, Hagge-Greenberg A Liedtke W, Soukas AA, Sharma R, Hudgins LC, Ntambi JM and Friedman JM: Role for stearoyl-CoA desaturase-1 in leptinmediated weight loss. Science 297: 240-243, 2002.

45. Waters KM and Ntambi JM: Insulin and dietary fructose induce stearoyl-CoA desaturase 1 gene expression of diabetic mice. J Biol Chem 269: 27773-27777, 1994.

46. Rahman SM, Dobrzyn A, Dobrzyn P, Lee SH, Miyazaki M and Ntambi JM: Stearoyl-CoA desaturase 1 deficiency elevates insulin-signaling components and down-regulates proteintyrosine phosphatase 1B in muscle. Proc Natl Acad Sci USA 100: $11110-11115,2003$.

47. Attie AD, Krauss RM, Gray-Keller MP, Brownlie A, Miyazaki M, Kastelein JJ, Lusis AJ, Stalenhoef AF, Stoehr JP, Hayden MR, et al: Relationship between stearoyl-CoA desaturase activity and plasma triglycerides in human and mouse hypertriglyceridemia. J Lipid Res 43: 1899-1907, 2002.

48. Kerner J and Hoppel C: Fatty acid import into mitochondria. Biochim Biophys Acta 1486: 1-17, 2000.

49. Chien D, Dean D, Saha AK, Flatt JP and Ruderman NB: Malonyl-CoA content and fatty acid oxidation in rat muscle and liver in vivo. Am J Physiol Endocrinol Metab 279: E259-E265, 2000.

50. Brand MD and Esteves TC: Physiological functions of the mitochondrial uncoupling proteins UCP2 and UCP3. Cell Metab 2: 85-93, 2005.

51. Nedergaard J and Cannon B: The 'novel' 'uncoupling' proteins UCP2 and UCP3: What do they really do? Pros and cons for suggested functions. Exp Physiol 88: 65-84, 2003.

52. Voss MD, Beha A, Tennagels N, Tschank G, Herling AW, Quint M, Gerl M, Metz-Weidmann C, Haun G and Korn M: Gene expression profiling in skeletal muscle of Zucker diabetic fatty rats: Implications for a role of stearoyl-CoA desaturase 1 in insulin resistance. Diabetologia 48: 2622-2630, 2005.

53. Ntambi JM: Regulation of stearoyl-CoA desaturase by polyunsaturated fatty acids and cholesterol. J Lipid Res 40: 1549-1558, 1999.

54. Choi Y, Kim YC, Han YB, Park Y, Pariza MW and Ntambi JM: The trans-10,cis-12 isomer of conjugated linoleic acid downregulates stearoyl-CoA desaturase 1 gene expression in 3T3-L1 adipocytes. J Nutr 130: 1920-1924, 2000. 